\title{
В.В. Николюк
}

\section{ОБЖАЛОВАНИЕ ПОТЕРПЕВШИМ ПОСТАНОВЛЕНИЙ СУДА ОБ УСЛОВНО-ДОСРОЧНОМ ОСВОБОЖДЕНИИ ОСУЖДЕННОГО ОТ ОТБЫВАНИЯ НАКАЗАНИЯ: ВОПРОСЫ ТЕОРИИ И ПРАКТИКИ}

\begin{abstract}
Анализируются уголовно-процессуальные новеллы, связанные с участием потерпевшего в стадии исполнения приговора. С учетом правовых позиций Верховного Суда РФ и Конституционного Суда РФ рассматривается право потерпевшего на апелляционное обжалование судебных решений об условнодосрочном освобождении осужденного от отбывания наказания.
\end{abstract}

Ключевые слова: условно-досрочное освобождение, исполнение приговора, потерпевший, суд, осужденный.

С учетом внесенных в российское законодательство в 2013 г. изменений и дополнений, направленных на повышение эффективности охраны прав и законных интересов потерпевших от преступлений (Федеральный закон от 23 июля 2013 г. № 221-Ф3 «О внесении изменений в статью 83 Уголовного кодекса Российской Федерации и статью 399 Уголовно-процессуального кодекса Российской Федерации»; Федеральный закон от 28 декабря 2013 г. № 432-Ф3 «О внесении изменений в отдельные законодательные акты Российской Федерации в целях совершенствования прав потерпевших в уголовном судопроизводстве»), последним предоставлена возможность реально влиять на принятие судом решения об условно-досрочном освобождении осужденного от отбывания наказания (далее - УДО). В первую очередь, это связано с правом участия потерпевшего в судебном заседании при рассмотрении соответствующего ходатайства осужденного, что закреплено в новой ч. 2.1 ст. 399 УПК РФ. Федеральный закон № 62-Ф3 от 30 марта 2015 г., внеся дополнения в ч. 2.1 ст. 399 УПК РФ и ряд других норм УПК РФ и УИК РФ, продолжил линию на укрепление правового статуса потерпевшего в стадии исполнения приговора, в частности расширил перечень случаев, когда он может участвовать в судебном заседании при рассмотрении судом вопросов, связанных с исполнением приговора (Федеральный закон от 30 марта 2015 г. № 62-Ф3 «О внесении изменений в Уголовно-процессуальный кодекс Российской Федерации и Уголовно-исполнительный кодекс Российской Федерации по вопросу участия потерпевших при рассмотрении судом вопросов, связанных с исполнением приговора»).

Правило, допустившее потерпевшего в судебное заседание по вопросам УДО, надлежит воспринимать в контексте, во взаимосвязи с правовой позицией Конституционного Суда РФ, сформулированной в Постановлении № 5-П от 18 марта 2014 г. по результатам рассмотрения дела о конституционности ч. 2.1. ст. 399 УПК РФ в связи с запросом Кетовского районного суда Курганской области. Суть ее может быть сведена к следующему:

a) участие потерпевшего в судебном заседании по вопросу УДО обусловлено возможностью содействия суду в принятии мер к обеспечению его личной безопасности, защиты его семьи и близких от угроз со стороны лица, совершившего преступление, возмещению причиненного этим преступлением вреда путем представления соответствующих документов, дачи объяснений, заявления ходатайств;

б) проведение судебного заседания в этом случае принципиально допустимо и без участия потерпевшего, которому было направлено соответствующее извещение по имеющемуся в распоряжении суда адpecy, поскольку сама по себе позиция потерпевшего не обусловливает, не предрешает разрешения ходатайства об условно-досрочном освобождении по существу;

в) в той мере, в какой ч. 2.1 ст. 399 УПК РФ предполагает в качестве условия рассмотрения судом ходатайства осужденного об УДО обязательность подтверждения получения потерпевшим извещения, уведомляющего о дате, времени и месте предстоящего судебного заседания, и в силу неопределенности механизма уведомления препятствует своевременному разрешению судом данного вопроса по существу, признана не соответствующей Конституции РФ.

Таким образом, в результате внесенных в 2013 г. изменений в УПК РФ (а также в УК РФ и УПК РФ) и правовой позиции Конституционного Суда РФ, выраженной в Постановлении № 5-П от 18 марта 2014 г., участие потерпевшего в делах об УдО стало принципиально возможным, но строго ограничено интересами обеспечения его личной безопасности, защиты его семьи и близких от угроз со стороны лица, совершившего преступление, реального возмещения причиненного преступлением вреда. В этой связи актуализировался важный в плане отстаивания потерпевшим своих прав и интересов вопрос об обжаловании в апелляционном порядке постановления суда об УДО. Это тем более значимо, если учесть, что ежегодно суды рассматривают большое количество соответствующих ходатайств осужденных (2010 г. - 207,3 тыс., 2011 г. - 190,8 тыс., 2012 г. 174,9 тыс., 2013 г. - 142,1 тыс.), из которых почти половина удовлетворяется [1, с. 44-46].

В юридической литературе аргументируются полярные, взаимоисключающие выводы в части наличия или отсутствия у потерпевшего права потерпев- 
шего на апелляционное (кассационное) обжалование судебных постановлений, вынесенных в порядке ст. 399 УПК РФ.

Часть ученых прямо заявляют, что закон не наделил его таким правом [2, с. $51 ; 3$, с. 161]. С.А. Синенко, например, пришел к выводу, что потерпевший не играет активной роли в рамках судебного производства по делам об условно-досрочном освобождении от наказания и замене не отбытой части наказания более мягким видом наказания. «Позиция потерпевшего, - пишет ученый, - не имеет правового значения при разрешении судом данных вопросов. Более того, ст. 399 УПК РФ в обновленном виде не предусматривает возможности доведения потерпевшим до суда своей позиции по существу рассматриваемого ходатайства. Да и трудно предположить, чтобы потерпевший, не имеющий доступа к информации о поведении осужденного в исправительном учреждении, мог привести какие-либо веские доводы об отсутствии предусмотренных законом оснований для его условно-досрочного освобождения от наказания. В этой связи необходимо иметь в виду, что постановления суда, вынесенные при рассмотрении вопросов, указанных в пП. 4 и 5 ст. 397 УПК РФ, не могут быть обжалованы потерпевшим. И это главное для реальной оценки процессуального статуса потерпевшего в рамках производства по данной категории дел» [4, с. 309-310 $]^{1}$.

Сторонники другой точки зрения полагают, что потерпевший должен иметь право знать сущность постановлений, вынесенных в порядке ст. 399 УПК РФ, и обжаловать их, присутствовать при разрешении ряда вопросов по исполнению приговора, иметь возможность влиять на решение суда [5, с. 86-87].

Специально обсуждался в процессуальной литературе и вопрос участия потерпевшего в судебном заседании, предметом которого является рассмотрение ходатайства осужденного об условно-досрочном освобождении от отбывания наказания. Утверждается, что потерпевший имеет личную заинтересованность, связанную с необходимостью защиты личной безопасности от возможных угроз со стороны осужденного или обеспечения возмещения причиненного преступлением материального ущерба [6, с. 27].

Идею активного участия потерпевшего в разрешении судом вопросов об условно-досрочном освобождении от отбывания наказания с правом обжалования принимаемых судебных решений отстаивает Л. В. Брусницын, позитивно оценивающий изменения в ст. 399 УПК РФ, осуществленные Федеральным законом от 23 июля 2013 г. № 221-Ф3 [7, c. $72 ; 8$, c. 89-96].

В опубликованном Верховным Судом РФ «Обзоре судебной практики условно-досрочного освобождения от отбывания наказания» вопрос о праве потерпевшего обжаловать в апелляционном порядке

\footnotetext{
${ }^{1}$ Надлежит обратить внимание на то, что данная точка зрения автором была высказана до принятия Конституционным Судом РФ постановления от 18 марта 2014 г. № 5-П.
}

постановление судьи об УдО не затрагивается, хотя в данном документе выделен специальный раздел 8.2 «Участие в судебном заседании потерпевшего, его законного представителя и (или) представителя» [1, c. 44-46].

В соответствии с ч. 3 ст. 399 УПК РФ в новой редакции потерпевший, участвующий в судебном заседании, вправе знакомиться с представленными в суд материалами, участвовать в их рассмотрении, заявлять ходатайства и отводы, давать объяснения, представлять документы. В этой части его права идентичны правам осужденного. Однако если в отношении последнего ни у кого не вызывает сомнений, что он вправе обжаловать в апелляционном порядке постановления судьи, принятые при исполнении приговоpa, что подтверждается судебной практикой, то применительно к потерпевшему ситуация несколько иная в силу того, что потерпевший ранее никогда не относился к участникам стадии исполнения приговора. Для ее прояснения обратимся к соответствующим нормам УПК РФ.

В ст. 401 УПК РФ «Обжалование постановления суда» записано общее правило о том, что на постановление суда, вынесенное при разрешении вопросов, связанных с исполнением приговора, могут быть поданы апелляционные жалобы или представление в порядке, установленном гл. 45.1 УПК РФ. В ней надлежит выделить ст. 389.1 «Право апелляционного обжалования», в которой потерпевший назван среди лиц, наделенных правом апелляционного обжалования судебного решения. Согласно п. 19 ч. 2 ст. 42 УПК РФ, потерпевший вправе обжаловать не только приговор, но и определение, постановление суда. Предусмотренные ст. 389.2 УПК РФ «Судебные решения, подлежащие апелляционному обжалованию» исключения из круга обжалуемых в апелляционном порядке судебных постановлений не проецируются на решения, принимаемые при исполнении приговора.

В специально посвященном вопросам апелляции Постановлении Пленума Верховного Суда РФ от 27 ноября 2012 г. № 26 «О применении норм Уголовно-процессуального кодекса Российской Федерации, регулирующих производство в суде апелляционной инстанции» разъяснено, что судебные решения могут быть обжалованы в апелляционном порядке, наряду с другими участниками и лицами, потерпевшими, их законными представителями и (или) представителями. А законные представители вправе обжаловать судебное решение и принимать участие в судебном заседании независимо от того, что к моменту производства по делу в суде апелляционной инстанции несовершеннолетнему потерпевшему исполнилось 18 лет [9, с. 2]. Руководствуясь данным разъяснением, следует исходить из того, что нет исключений для апелляционного обжалования потерпевшим (его законным представителем и представителем) судебных постановлений, вынесенных по результатам рассмотрения ходатайств осужденных об УДО. 
Следовательно, потерпевший, будучи допущенным в судебное заседание по вопросу об УдО, вправе обжаловать в апелляционном порядке постановление судьи, вынесенное по результатам рассмотрения соответствующего ходатайства осужденного. Данный вывод отражает произошедшие изменения в уголовно-процессуальном законодательстве ${ }^{2}$. В этом направлении начинает складываться и судебная практика.

Так, например, 31 октября 2011 г. С. осужден приговором Выксунского городского суда Нижегородской области по ч. 3 ст. 264 УК РФ к 3 годам лишения свободы, с лишением права управления транспортным средством на 3 года, с отбыванием наказания в колонии-поселении. Этим же приговором с осужденного в пользу потерпевшей В. в счет возмещения морального вреда взыскано 800 тыс. руб., материального вреда 80 тыс. руб.

Постановлением Электростальского городского суда Московской области от 30 сентября 2014 г. удовлетворено ходатайство осужденного С. об условно-досрочном освобождении (не отбытый срок составил 9 месяцев 29 дней). Суд обязал осужденного, наряду с другими обязанностями, выплатить потерпевшей В. оставшуюся часть средств по гражданскому иску.

Не согласившись с таким решением суда, потерпевшая В. обратилась в суд апелляционной инстанции с жалобой и выразила просьбу отменить постановление суда по следующим мотивам: осужденный С. вину не признал, в содеянном не раскаялся, не принес извинений в связи с гибелью ее сына, гражданский иск о возмещении морального и материального вреда не погасил, выплаченная сумма в размере 22 тыс. руб. из присужденных 880 тыс. руб. незначительна.

Рассмотрев в судебном заседании 18 ноября 2014 г. апелляционную жалобу потерпевшей В., судья Московского областного суда отменил постановление Электростальского городского суда Московской области об условно-досрочном освобождении С. от отбытия оставшейся части наказания, жалобу удовлетворил, указав, что отношение осужденного С. к возмещению причиненного преступлением вреда, выразившееся в том, что он за период более 4 лет возместил только 22 тыс. руб., указывает на отсутствие у него стремления встать на путь исправления и быть освобожденным от наказания условно-досрочно. При этом, отметил суд апелляционной инстанции, объективных причин, таких, как инвалидность осужденного, наличие у него заболеваний, препятствующих трудоустройству, невозможность трудоустройства из-за ограниченного количества рабочих мест в колонии, затрудняющих возмещение ущерба потерпевшему, в судебном заседании не установлено [11].

\footnotetext{
${ }^{2}$ В процессуальной литературе применительно к ранее действовавшему законодательству правильно отмечалось, что потерпевший не назывался в составе лиц, имеющих право приносить жалобы на судебные постановления, принятые в порядке исполнения приговора [10, с. 79].
}

Еще один пример: 11 декабря 2014 г. судья Красноярского краевого суда отменил в апелляционном порядке по жалобам потерпевших постановление Нижнеингашского районного суда Красноярского края от 7 октября 2014 г. об условно-досрочном освобождении от не отбытой части наказания К., вынес по ходатайству осуждённого К. новое судебное решение, которым в удовлетворении ходатайства об условно-досрочном освобождении от наказания, назначенного по приговору Советского районного суда г. Красноярска от 16 января 2012 г., отказал. Данное апелляционное постановление мотивировано, в частности, следующим.

При наличии общей суммы установленного судом причинённого совершёнными по делу действиями, по которому был постановлен последний приговор, ущерба более 12 млн руб., осуждённым представлены суду доказательства принятия им мер к возмещению ущерба по удовлетворённым судом гражданским искам одиннадцати потерпевших на общую сумму 10989415 руб. 88 коп. только в размеpe 10801 руб. 85 коп., то есть менее $0,1 \%$ от взысканной суммы, а также полного возмещения причинённого одному потерпевшему ущерба до постановления последнего приговора в размере 3300 руб.

При этом им не представлены данные о принятых им мерах по возмещению ущерба потерпевшим А. в сумме 50000 руб., Г. - 100000 руб., Е. - 240000 руб., И. -170000 руб., К. - 46000 руб., Л. -51000 руб., П. - 150000 руб., Ш. - 500000 руб., оставшейся невозмещённой части ущерба потерпевшему по делу.

Указанные обстоятельства с учётом усматриваемых из содержания приговора данных о размере похищенных денежных средств, о принятии осуждённым до его заключения под стражу мер к приобретению на похищенные денежные средства дорогостоящего имущества, в частности автомобилей с их регистрацией на других лиц, непринятии им мер к выдаче органам следствия всего им похищенного не позволяли суду прийти к выводу о принятии осуждённым исчерпывающих мер к возмещению причинённого преступлениями ущерба, а следовательно, и к выводу об исправлении осуждённого и отсутствии необходимости в дальнейшем отбывании им наказания [12].

С признанием за потерпевшим права апелляционного обжалования судебных постановлений об УДО осужденного такое право надлежит признать, с учетом содержания ст. 389.1 УПК РФ, и за законным представителем и представителем потерпевшего. Причем указанные лица, как это следует из позиции Верховного Суда РФ по данному вопросу, вправе обжаловать данные судебные решения независимо от того, участвовали ли они в судебном заседании при рассмотрении ходатайства осужденного об УДО. Так, Пленум Верховного Суда РФ в п. 35 Постановления от 29 июня 2010 г. «О практике применения судами норм, регламентирующих участие потерпевшего в уголовном судопроизводстве» разъяснил, что суд, постановивший приговор или 
вынесший иное судебное решение, извещает о принесенных жалобе или представлении и направляет их копии потерпевшему и его законному представителю, а также гражданскому истцу и его представителю, если жалоба или представление затрагивают их интересы, с разъяснением возможности подачи на жалобу или представление возражений. Указанные лица уведомляются о дне рассмотрения дела вне зависимости от того, участвовали ли они в судебном заседании [13, с. 8$]$.

В заключение следует сделать вывод, что в результате изменений и дополнений, внесенных в УПК РФ в 2013 г., потерпевший стал потенциальным участником судебного производства, осуществляемого в порядке главы 47 УПК РФ, и субъектом права на апелляционное обжалование всех решений, принимаемых при исполнении приговора, когда они затрагивают его интересы. Впервые в отечественной практике уголовного судопроизводства суды стали принимать к апелляционному рассмотрению жалобы потерпевших, не согласных с условно-досрочным освобождением осужденного в связи с неполным возмещением им вреда, причиненного преступлением.

Вместе с тем в теоретическом и прикладном аспектах дополнительно предстоит выработать позицию по следующему вопросу: «Насколько юридически значима жалоба потерпевшего на постановление об УдО осужденного, если жалоба не связана с обеспечением его личной безопасности, защиты его семьи и близких от угроз со стороны лица, совершившего преступление, возмещением причиненного этим преступлением вреда?» Если исходить из того, что «влияние» потерпевшего на УДО осужденного строго ограничено интересами обеспечения его личной безопасности, защиты его семьи и близких от угроз со стороны лица, совершившего преступление, реального возмещения причиненного преступлением вреда, подобная жалоба не имеет судебной перспективы. Тогда каким образом апелляционный суд должен реагировать на нее: 1) отказать в принятии жалобы к рассмотрению и возвратить ее потерпевшему? 2) принять жалобу к рассмотрению и прекратить производство по ней? 3) принять жалобу к рассмотрению и отказать в ее удовлетворении?

Можно прогнозировать, что в судебной практике в этой части будут иметь место все три варианта реагирования судов на такие жалобы потерпевших. Поэтому правоприменитель вправе ожидать соответствующих разъяснений от Пленума Верховного Суда РФ. Это тем более важно, поскольку в перспективе не исключено распространение правила, закрепленного в ч. 2.1. ст. 399 УПК РФ, на другие дела (п. $6,8,8^{1}, 14,17^{1}$ ст. 397 УПК РФ), когда суд может улучшить, порой самым серьезным образом, положение осужденного в сравнении с тем, как оно определено в приговоре.

\section{ЛИТЕРАТУРА}

1. Бюллетень Верховного Суда РФ. 2014. № 8.

2. Улицкий С. Новые вопросы в практике условно-досрочного освобождения // Рос. юстиция. 2004. № 2. С. 50-52.

3. Воронин O.B. Производство по рассмотрению и разрешению вопросов, связанных с условно-досрочным освобождением. Томск: Изд-во НТЛ, 2004. 208 с.

4. Синенко С.А. Обеспечение прав и законных интересов потерпевшего в уголовном судопроизводстве : Дис. ... докт. юрид. наук. Хабаровск, 2014. 330 с.

5. Левченко O.B., Камардина А.A. Реализация принципов уголовного судопроизводства судом в стадии исполнения приговора. М.: Юрлитинформ, 2013. 192 с.

6. Рябиов Ю.А., Гричаниченко А. В. Об участии потерпевших при решении вопросов, связанных с исполнением приговора // Уголовное судопроизводство. 2012. № 2. С. 27-29.

7. Бруснищын Л. В. Участие потерпевшего в уголовном процессе: какие сложности для правоприменителей создали разъяснения Пленума Верховного Суда РФ // Уголовный процесс. 2011. № 2. С. 72-74

8. Бруснищын Л.В. О правах потерпевшего в стадии исполнения приговора // Уголовное право. 2013. № 6. С. 89-96.

9. Бюллетень Верховного Суда РФ. 2013. № 1. С. 2.

10. Червоткин А.С. Апелляция и кассация: пособие для судей. М.: Проспект, 2010. 336 с.

11. Архив Московского областного суда за 2014 г., дело № 22-6739.

12. Архив Красноярского краевого суда, дело № 22-8243/2014.

13. Бюллетень Верховного Суда РФ. 2010. № 9.

\section{THE VICTIM'S CHALLENGING THE COURT DECISION ON PAROLE OF THE CONVICT FROM SERVING} THE PUNISHMENT: THEORY AND PRACTICE

Russian Journal of Criminal Law, 2015, 1(5), 40-44. DOI 10.17223/23088451/5/7

Nikolyuk Vyacheslav V. Orel Law Institute of Ministry of Interior of the Russian Federation (Orel, Russian Federation). E-mail: nvv56@mail.ru

Keywords: parole, sentence, victim, court, convict.

In accordance with amendments and additions in the Code of Criminal Procedure of 2013, the victim has become a potential participant in the court proceedings under Chapter 47 of the Code of Criminal Procedure of the Russian Federation, and the subject of the right to appeal against all decisions referring to the execution of the sentence, if they affect their interests. For the first time in the Russian criminal proceedings the courts have begun to take to the appellate proceedings complaints from victims who disagree with the parole of the convict in due to their partial compensation for damage caused by the crime. 
However, it is necessary to work out a position on the following question: "How legally important is the complaint of the victim about the parole of the convict, if the complaint is not related to ensuring their personal safety, protection of their family and friends from threats of the perpetrator of the crime or to the compensation for damage?" Assuming that the "influence" of the victim on the parole of the convict is strictly limited to ensuring their personal safety, protection of their family and friends from threats of the perpetrator, real compensation for the damage caused by the crime, such a complaint has no judicial perspective. Then, how should the Court of Appeal react to it? Should it 1) refuse to accept the complaint for consideration and return it to the victim? 2) accept the complaint for consideration and terminate it then? 3) accept the complaint for consideration and deny its satisfaction?

It is possible to predict that the judicial practice will take embrace all three options to respond to such complaints. Therefore, law enforcers can expect clarifications from the Supreme Court of the Russian Federation. This is all more important because, in the long run, the rule set out in Chapter 2.1 of Article 399 of the Code of Criminal Procedure of the Russian Federation can cover other cases (Paragraphs 6, 8, 81, 14, 171 of Article 397 of the Code of Criminal Procedure of the Russian Federation), when the court can improve the position of the convict in comparison with what is given in the verdict.

\section{REFERENCES}

1. Byulleten' Verkhovnogo Suda RF. (2014) 8.

2. Ulitsky S. (2004) Novye voprosy v praktike uslovno-dosrochnogo osvobozhdeniya [New issues in the practice of parole]. Rossiuskaya yustitsiya - Russian Justice. 2. pp. 50-52.

3. Voronin O.V. (2004) Proizvodstvo po rassmotreniyu i razresheniyu voprosov, svyazannykh s uslovno-dosrochnym osvobozhdeniem [Proceedings of trial and decision of questions related to parole]. Tomsk: Izd-vo NTL.

4. Sinenko S.A. (2014) Obespechenie prav i zakonnykh interesov poterpevshego v ugolovnom sudoproizvodstve [Ensuring the rights and legitimate interests of the victim in criminal proceedings]. Law Dr. Diss. Khabarovsk.

5. Levchenko O.V. \& Kamardina A.A. (2013) Realizatsiya printsipov ugolovnogo sudoproizvodstva sudom v stadii ispolneniya prigovora [Implementation of the principles of criminal proceedings by a court in the stage of execution]. Moscow: Yurlitinform.

6. Ryabtsov Yu.A. \& Grichanichenko A.V. (2012) Ob uchastii poterpevshikh pri reshenii voprosov, svyazannykh s ispolneniem prigovora [The participation of victims in issues related to the execution of the sentence]. Ugolovnoe sudoproizvodstvo Criminal Judicial Proceeding. 2. pp. 27-29.

7. Brusnitsyn L.V. (2011) Uchastie poterpevshego v ugolovnom protsesse: kakie slozhnosti dlya pravoprimeniteley sozdali raz"yasneniya Plenuma Verkhovnogo Suda RF [Participation of the victim in the criminal process: what challenges for enforcers were caused by the explanations of the Plenum of the Supreme Court of the Russian Federation]. Ugolovnyy protsess. 2. pp. $72-74$

8. Brusnitsyn L.V. (2013) About the Victim's Rights at the Stage of Execution of Sentence. Ugolovnoe pravo. 6. pp. 89-96.

9. Byulleten' Verkhovnogo Suda RF. (2013). 1. p. 2.

10. Chervotkin A.S. (2010) Apellyatsiya i kassatsiya [Appeal and cassation]. Moscow: Prospekt.

11. The Archive of the Moscow Regional Court for 2014. Case 22-6739. (In Russian).

12. The Archive of the Krasnoyarsk Regional Court. Case 22-8243/2014. (In Russian).

13. Byulleten' Verkhovnogo Suda RF. (2010). 9. 